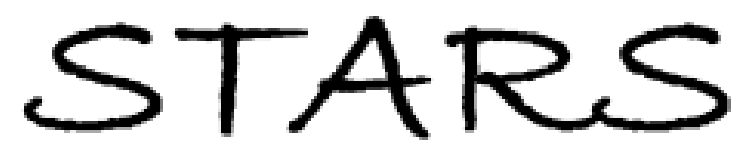

University of Central Florida

STARS

$1-1-2007$

\title{
Electric-pulse-induced reversible resistance in doped zinc oxide thin films
}

\author{
M. Villafuerte \\ S. P. Heluani \\ G. Juàrez \\ G. Simonelli \\ G. Braunstein \\ University of Central Florida
}

See next page for additional authors

Find similar works at: https://stars.library.ucf.edu/facultybib2000 University of Central Florida Libraries http://library.ucf.edu

This Article is brought to you for free and open access by the Faculty Bibliography at STARS. It has been accepted for inclusion in Faculty Bibliography 2000s by an authorized administrator of STARS. For more information, please contact STARS@ucf.edu.

\section{Recommended Citation}

Villafuerte, M.; Heluani, S. P.; Juàrez, G.; Simonelli, G.; Braunstein, G.; and Duhalde, S., "Electric-pulseinduced reversible resistance in doped zinc oxide thin films" (2007). Faculty Bibliography 2000s. 7752. https://stars.library.ucf.edu/facultybib2000/7752

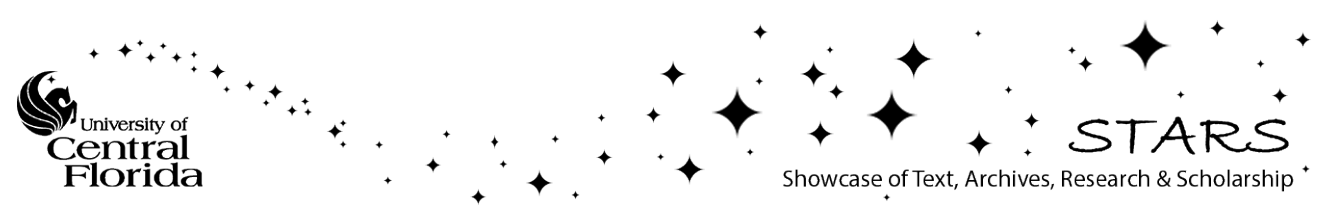


Authors

M. Villafuerte, S. P. Heluani, G. Juàrez, G. Simonelli, G. Braunstein, and S. Duhalde 


\section{Electric-pulse-induced reversible resistance in doped zinc oxide thin films}

Cite as: Appl. Phys. Lett. 90, 052105 (2007); https://doi.org/10.1063/1.2437688

Submitted: 21 October 2006 . Accepted: 03 January 2007 . Published Online: 30 January 2007

M. Villafuerte, S. P. Heluani, G. Juárez, G. Simonelli, G. Braunstein, and S. Duhalde

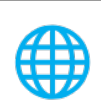

View Online

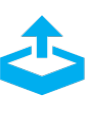

\section{ARTICLES YOU MAY BE INTERESTED IN}

Unipolar resistive switching characteristics of $\mathrm{ZnO}$ thin films for nonvolatile memory applications

Applied Physics Letters 92, 022110 (2008); https://doi.org/10.1063/1.2834852

Characteristics and mechanism of conduction/set process in $\mathrm{TiN} / \mathrm{ZnO} / \mathrm{Pt}$ resistance switching random-access memories

Applied Physics Letters 92, 232112 (2008); https://doi.org/10.1063/1.2945278

Electrode dependence of resistive switching in $\mathrm{Mn}$-doped $\mathrm{ZnO}$ : Filamentary versus interfacial mechanisms

Applied Physics Letters 96, 192113 (2010); https://doi.org/10.1063/1.3428365

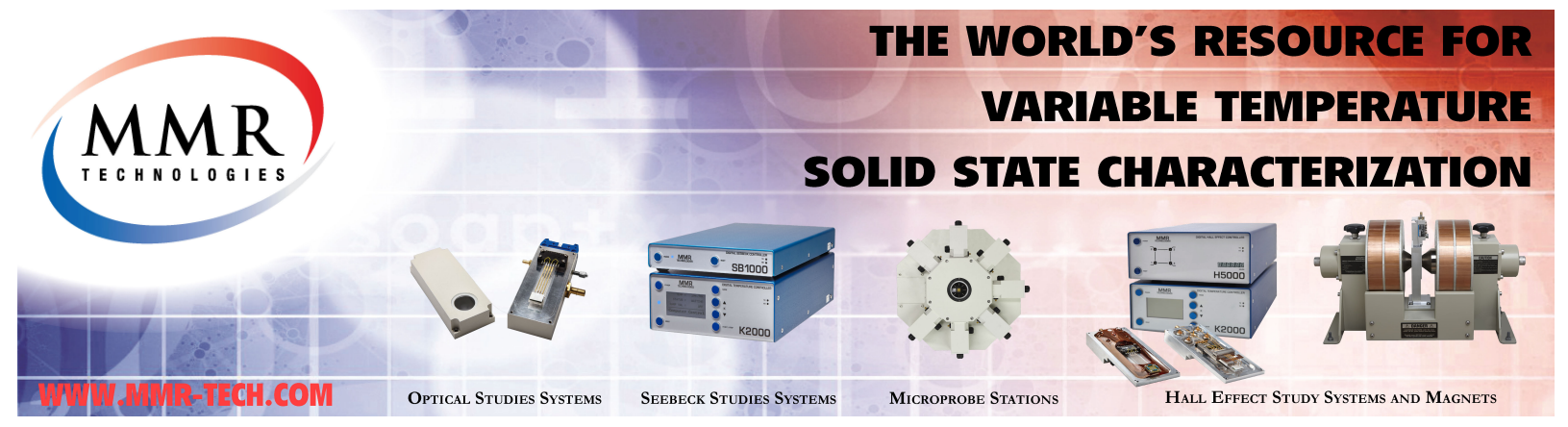




\title{
Electric-pulse-induced reversible resistance in doped zinc oxide thin films
}

\author{
M. Villafuerte, S. P. Heluani, G. Juárez, and G. Simonelli \\ Laboratorio de Física del Sólido, Departamento de Física, Facultad de Ciencias Exactas y Tecnología, \\ Universidad Nacional de Tucumán, T4002BLR San Miguel de Tucumán, Argentina \\ G. Braunstein ${ }^{\text {a) }}$ \\ Department of Physics, University of Central Florida, Orlando, Florida 32816 \\ S. Duhalde \\ Laboratorio de Ablación Láser, Facultad de Ingeniería, Universidad de Buenos Aires, C1063ACV Ciudad \\ Autónoma de Buenos Aires, Argentina
}

(Received 21 October 2006; accepted 3 January 2007; published online 30 January 2007)

\begin{abstract}
Nonvolatile, electric-pulse-induced resistance switching is reported on $\mathrm{S}$ and Co doped $\mathrm{ZnO}$ thin films deposited on different substrates using magnetron sputtering and laser ablation. Two resistance states were obtained by applying voltage pulses of different polarity. The switching was observed regardless of the substrate, dopant species, or microstructure of the samples. In the Co doped $\mathrm{ZnO}$ samples, the two resistance states are remarkably stable and uniform. (C) 2007 American Institute of Physics. [DOI: 10.1063/1.2437688]
\end{abstract}

Resistance switching and voltage controlled negative resistance phenomena have been observed since the 1960s on materials such as amorphous semiconductors ${ }^{1-3}$ and $\mathrm{ZnSe}-\mathrm{Ge}$ heterostructures, ${ }^{4}$ as well as on a variety of oxides such as $\mathrm{Nb}_{2} \mathrm{O}_{5},{ }^{5} \mathrm{Al}_{2} \mathrm{O}_{3},{ }^{6} \mathrm{Ta}_{2} \mathrm{O}_{5},{ }^{7} \mathrm{TiO}_{2},{ }^{8}$ and $\mathrm{NiO}$. ${ }^{9,10}$ An apparently related phenomenon, known as electric-pulseinduced resistance switching (EPIR), has been recently reported in $\operatorname{Pr}_{0.7} \mathrm{Ca}_{0.3} \mathrm{MnO}_{3}$ thin films at room temperature. ${ }^{11}$ In this effect, a nonvolatile change of the electrical resistance between two electrodes is observed after applying an electric pulse. Thus, the EPIR effect is different from "conventional" resistance switching, where the effect vanishes as the bias is reduced. ${ }^{12}$ Furthermore, the direction of the resistance change (i.e., either increased or decreased resistance) depends on the polarity of the electric pulse in EPIR.

In this work, we report a reproducible EPIR effect in doped $\mathrm{ZnO}$. Thin films of $\mathrm{ZnO}$ doped with sulfur and cobalt and deposited using magnetron sputtering and laser ablation, respectively, exhibit the switching behavior characteristic of the EPIR effect, without the need of previous sample training. In particular, in the $\mathrm{Co}$ doped $\mathrm{ZnO}$ samples, the resistance is remarkably stable and uniform in both the low and the high resistance states.

Thin films of $\mathrm{ZnO}$ were fabricated by two methods: (a) pure $\mathrm{ZnO}$ and sulfur doped $\mathrm{ZnO}$ films $(\mathrm{S}: \mathrm{ZnO})$ were deposited by radio frequency magnetron sputtering at room temperature in argon atmosphere on $\mathrm{SiO}_{2} / \mathrm{Si}$ and on $\mathrm{Si}$ substrates and (b) cobalt doped $\mathrm{ZnO}$ films $(\mathrm{Co}: \mathrm{ZnO})$ were grown on $\mathrm{Si}_{3} \mathrm{~N}_{4} / \mathrm{Si}$ substrates by pulsed laser deposition (PLD) at $400{ }^{\circ} \mathrm{C}$ under $5 \mathrm{~Pa}$ of nitrogen (using a $\mathrm{ZnO}$ target with a nominal Co content of $15 \%$ ). The thickness of all the films was about $100 \mathrm{~nm}$, as estimated form secondary ion mass spectrometry and Rutherford backscattering spectrometry measurements. X-ray diffraction (XRD) patterns corresponded to the $\mathrm{ZnO}$ wurtzite structure for all the films. The sputtered $\mathrm{ZnO}$ and $\mathrm{S}: \mathrm{ZnO}$ films were polycrystalline although textured with the $c$ axis $(c=0.507 \pm 0.001 \mathrm{~nm})$ per-

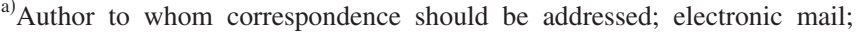
braunstein@physics.ucf.edu pendicular to the substrate. The $\mathrm{Co:} \mathrm{ZnO}$ films were found to be highly oriented, with the $c$ axis $(c=0.516 \pm 0.001 \mathrm{~nm})$ aligned perpendicular to the substrate, and exhibit only (002) and (004) XRD lines. For the electrical transport measurements, leads were soldered with Ag epoxy to round Au contacts sputtered on the top surface of the samples. A twoprobe configuration, in constant voltage mode, was employed. Figure 1 illustrates schematically the setup used for $I-V$ characterization and pulse application. The currentvoltage curves ( $I-V$ curves) were constructed using tension pulses of increasing amplitude and about $1 \mathrm{~s}$ duration, each followed by about half a second without applied tension in order to minimize potential Joule heating. To study the EPIR effect, short high-voltage pulses $(40 \mathrm{~ms})$ were applied using a Keithley 220 programmable current source, and current flow upon low voltage bias $(\leqslant 1 \mathrm{~V})$ was monitored through the voltage drop across a known resistor $(1 \mathrm{k} \Omega)$ using a Keithley 182 nanovoltmeter. Positive bias was defined by the current flowing from electrode A to electrode B (see Fig. 1), and negative bias was defined by the opposite direction. The measurements were made in a vacuum of $\sim 1$ mTorr and at room temperature.

Figure 2(a) shows the $I$ - $V$ curve for a $\mathrm{S}: \mathrm{ZnO}$ film deposited by sputtering on a $\mathrm{SiO}_{2} / \mathrm{Si}$ substrate. The resistance as a function of applied voltage, calculated from the $I-V$ data, is shown in the inset. Initially, the film exhibited high resistivity. However, the number of charge carriers could be en-

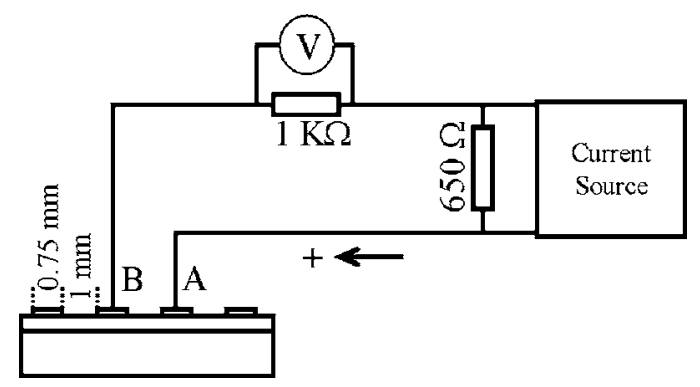

FIG. 1. Setup used for pulse application and current-voltage (I-V) characterization. 

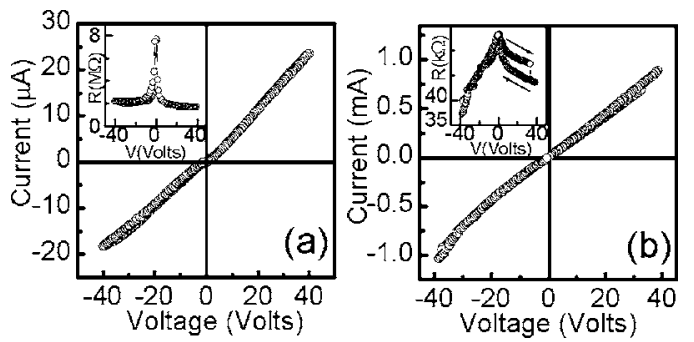

FIG. 2. Current voltage $(I-V)$ characteristics of (a) a sulfur doped $\mathrm{ZnO}$ sample deposited on $\mathrm{SiO}_{2} / \mathrm{Si}$ substrate (measured under UV illumination) and (b) a cobalt doped $\mathrm{ZnO}$ film deposited on $\mathrm{Si}_{3} \mathrm{~N}_{4} / \mathrm{Si}$. The inset shows the calculated resistance as a function of voltage.

hanced, and the resistivity reduced, by irradiation before (for $\sim 1 \mathrm{~h}$ ) and during measurement with ultraviolet (UV) light. For this purpose, an OSRAM ${ }^{\mathrm{TM}}$ ULTRAVITALUX lamp of $300 \mathrm{~W}$, with two main intensity peaks at 310 and $360 \mathrm{~nm}$, was used. An undoped $\mathrm{ZnO}$ sample deposited on a $\mathrm{SiO}_{2} / \mathrm{Si}$ substrate showed a similar $I-V$ curve (not shown), but with much higher values of resistance (between 300 and $500 \mathrm{M} \Omega$ ). The $I-V$ curve (measured in the dark) of the $\mathrm{S}: \mathrm{ZnO}$ film deposited on a Si substrate (not shown) exhibited stronger nonlinearity and lower resistance $(\sim 2-\sim 100 \mathrm{~K} \Omega$, depending on applied voltage) than the sample shown in Fig. 2(a). Figure 2(b) shows the $I-V$ curve for a Co: $\mathrm{ZnO}$ film deposited by PLD on a $\mathrm{Si}_{3} \mathrm{~N}_{4} / \mathrm{Si}$ substrate. As can be seen from the inset in Fig. 2(b), there is a resistance switch at the positive branch of the $I-V$ curve. This feature is not detected in the $I-V$ curves of the films deposited by sputtering.

Figures 3(a) and 3(b) show the voltage pulse driven high-resistance-low-resistance switching for the $\mathrm{S}: \mathrm{ZnO}$ samples deposited on $\mathrm{SiO}_{2} / \mathrm{Si}$ and $\mathrm{Si}$, respectively. The measurement process consisted in using a "read" voltage of +0.1 or $+1 \mathrm{~V}$ to monitor the resistance of the sample and a sequence of 15 consecutive pulses of $\pm 40 \mathrm{~V}$ and $40 \mathrm{~ms}$ of duration each to switch the resistance. The number of pulses in the sequence was chosen in order to observe a clear and reproducible effect, although a series of less pulses would also induce the resistance switch. Figure 3(a) shows that, after the group of 15 pulses of $+40 \mathrm{~V}$ is applied, the resistance switches to a low resistance state. Then, after the series of 15 pulses of $-40 \mathrm{~V}$, the resistance reverts to its original higher value. Both films switched to low resistance after $(+)$ pulses and reverted to high resistance after (-) pulses. Figure 3(a) also shows that the high resistance values are unsteady, showing a capacitive effect common in resistive materials. Figure 3(b) shows a similar effect, but without the capacitive decay, in the more conductive $\mathrm{ZnO} / \mathrm{Si}$ sample. The undoped $\mathrm{ZnO}$ sample analyzed in the present study did not exhibit the switching effect. Figure 3(c) shows the voltage pulse driven, high-resistance-low-resistance switching for the $\mathrm{Co}: \mathrm{ZnO}$ sample. It is observed that the film switches to a low resistance state after $(+)$ pulses and reverts to a high resistance state after $(-)$ pulses in a similar way as the $\mathrm{S}: \mathrm{ZnO}$ samples. However, in the case of the $\mathrm{Co}: \mathrm{ZnO}$ sample, the resistance is remarkably more stable and uniform in both the low and the high resistance states.

We do not have yet a definitive explanation for the EPIR effect in doped $\mathrm{ZnO}$. Indeed, the physical origin of the resistance switch in other materials, where the effect was observed previously, is still under intense debate and different
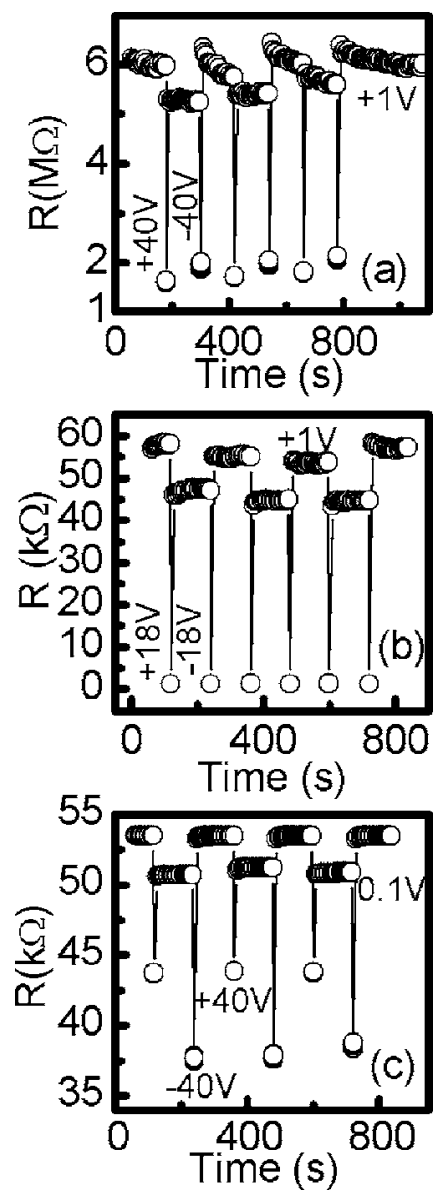

FIG. 3. Resistance response of $\mathrm{ZnO}$ films in (a) sulfur doped $\mathrm{ZnO}$ film on $\mathrm{SiO}_{2} / \mathrm{Si}$ substrate (measured under UV illumination at $300 \mathrm{~K}$ ) when an alternate series of voltage pulses of +40 and $-40 \mathrm{~V}$ is applied every $120 \mathrm{~s}$, (b) sulfur doped $\mathrm{ZnO}$ film on Si substrate (measured in the dark at $290 \mathrm{~K}$ ) when an alternate series of voltage pulses of +18 and $-18 \mathrm{~V}$ is applied every $120 \mathrm{~s}$, and (c) cobalt doped $\mathrm{ZnO}$ film deposited by pulsed laser deposition on $\mathrm{Si}_{3} \mathrm{~N}_{4} / \mathrm{Si}$ (measured in the dark at $290 \mathrm{~K}$ ) when an alternate series of voltage pulses of +40 and $-40 \mathrm{~V}$ is applied every $120 \mathrm{~s}$.

models have been proposed. ${ }^{11,13-17}$ In previous works on the electrical transport properties of polycrystalline $\mathrm{ZnO}$ thin films, ${ }^{18-20}$ we have shown that the electrical conductivity of $\mathrm{ZnO}$ is modulated by effects induced by bulk and grain boundary defect states. In order to guide future work, we have adopted the working hypothesis that defect states (in the bulk and at the $\mathrm{ZnO} /$ metal interfaces) are responsible, directly or indirectly, for the resistance switching effect. Traps sufficiently deep to have trapping times of tens of seconds or more have been detected in $\mathrm{ZnO},{ }^{21,22}$ and carrier trapping has been recently suggested as the origin of resistance switching in manganites. ${ }^{23}$ Further work is in progress to test the validity of these assumptions and elucidate the physical mechanisms responsible for resistance switching in polycrystalline $\mathrm{ZnO}$ thin films.

The work carried out at UNT was partially supported by CIUNT under Grant Nos. E328, E337 and FONCYT. The work at UCF was partially supported by the National Science Foundation under Grant No. DMR 0406502.

${ }^{1}$ S. R. Ovshinsky, Phys. Rev. Lett. 36, 1469 (1968).

${ }^{2}$ J. F. Dewald, A. D. Pearson, W. R. Northover, and W. F. Peck, Jr., J. Electrochem. Soc. 109, 243c (1962).

${ }^{3}$ G. Dearnaley, A. M. Stoneham, and D. V. Morgan, Rep. Prog. Phys. 33, 1129 (1970). 
${ }^{4}$ H. J. Hovel and J. J. Urgell, J. Appl. Phys. 42, 5076 (1971).

${ }^{5}$ W. R. Hiatt and T. W. Hickmott, Appl. Phys. Lett. 6, 106 (1965).

${ }^{6}$ T. W. Hickmott, J. Vac. Sci. Technol. 6, 828 (1969).

${ }^{7}$ K. L. Chopra, J. Appl. Phys. 36, 184 (1965).

${ }^{8}$ F. Argall, Solid-State Electron. 11, 535 (1968).

${ }^{9}$ J. F. Gibbons and W. E. Beadle, Solid-State Electron. 7, 785 (1964).

${ }^{10}$ J. C. Bruyere and B. K. Chakraverty, Appl. Phys. Lett. 16, 40 (1970).

${ }^{11}$ S. Q. Liu, N. J. Wu, and A. Ignatiev, Appl. Phys. Lett. 76, 2749 (2000).

${ }^{12}$ M. Hamaguchi, K. Aoyama, S. Asanuma, Y. Uesu, and T. Katsufuji, Appl. Phys. Lett. 88, 142508 (2006).

${ }^{13}$ R. Fors, S. I. Khartsev, and A. M. Grishin, Phys. Rev. B 71, 045305 (2005).

${ }^{14}$ A. Baikalov, Y. Q. Wang, B. Shen, B. Lorenz, S. Tsui, Y. Y. Sun, Y. Y. Xue, and C. W. Chu, Appl. Phys. Lett. 83, 957 (2003).

${ }^{15}$ J. Ventura, J. B. Sousa, Y. Liu, Z. Zhang, and P. P. Freitas, Phys. Rev. B 72, 094432 (2005).
${ }^{16}$ C. Rossel, G. I. Meijer, D. Brémaud, and D. Widmer, J. Appl. Phys. 90, 2892 (2001).

${ }^{17}$ M. J. Rozenberg, I. H. Inoue, and M. J. Sanchez, Phys. Rev. Lett. 92, 178302 (2004).

${ }^{18}$ S. P. Heluani, G. Simonelli, M. Villafuerte, G. Juarez, A. Tirpak, G. Braunstein, and F. Vignolo, Mater. Res. Soc. Symp. Proc. 829, B2.25.1 (2005).

${ }^{19}$ S. P. Heluani, G. Braunstein, M. Villafuerte, G. Simonelli, and S. Duhalde, Thin Solid Films 515, 2739 (2006).

${ }^{20}$ O. Hamad, G. Braunstein, H. Patil, and N. Dhere, Thin Solid Films 489, 303 (2004)

${ }^{21}$ Y. Nakano, T. Morikawa, T. Ohwoki, and Y. Taga, Appl. Phys. Lett. 87, 232104 (2005).

${ }^{22}$ K. Moazzami, T. E. Murphy, J. D. Phillips, M. C.-K. Cheung, and A. N. Cartwright, Semicond. Sci. Technol. 21, 717 (2006).

${ }^{23}$ D. S. Shang, Q. Wang, L. D. Chen, R. Dong, X. M. Li, and W. Q. Zhang, Phys. Rev. B 73, 245427 (2006). 